\title{
Sexualisation of Women in Nigerian Advertorial English Medium Bill Board
}

\author{
Bolanle Tajudeen Opoola \\ Federal University, Oye Ekiti, Nigeria \\ Folorunso, Emmanuel Awoniyi \\ Osun State University, Osogbo, Nigeria
}

\begin{abstract}
This paper surveys sexism in English, citing selected communicative instances in English medium billboards in Ile Ife, Osun State, Nigeria. The photographs and written inscriptions on the selected billboards depict the stereotypical representation of women as weaker species and exertion of men power over women. This was achieved through a critical discourse analysis of visual and verbal language discourses in ten randomly selected English medium billboards selected as sources of gathering data for this research. In Nigeria, billboards are meant for public announcements and advertisements. They also convey information about products and company services. Findings of this research among others reveal that there is asymmetrical power relation in terms of dominance and subordination between men and women as demonstrated by the portrayal of men in terms of physical attribute, such as strength, vigor, and a daring ability, as against the portrayal of women in terms of sex appealing, physical attractiveness as well as concerned with trivial, unserious and playful things. The study advocates for equal treatment of men and women without unnecessary sex differentiation.
\end{abstract}

Index Terms—billboards, sexism, communication, discourse analysis

\section{INTRODUCTION}

Sexism is a treatment that expresses bias in favor of one sex and thus treats the other sex in a discriminatory manner, Lei (2006). The society in which we live particularly in Nigeria is presumably a male dominated one that has the bulk of its prejudice and discrimination against women. This is evident in the way women are barred from certain occupation, positions, and behaviors and are defined only by what the society expects from them. Considering a nurse to be only female until the recent time, and an astronaut to be male is something quite common, Ahmed (2009). However, in recent times, especially in most first world countries like America and Britain and in some third world countries, like Nigeria and Liberia, it is not uncommon to see women occupying political and religious positions, influencing the economic sector, taking up activists positions for fellow women, and even refusing to conform with some cultural aspects of the society, like letting go of their maiden names after marriage. However, though both the male and the female gender are considered equal in most countries, sexism still exists, having been made so subtle and obscure in such a way that people conform to and uphold sexism without even realizing it. Over the years, studies have revealed that this phenomenon is not only entrenched in the economic, political, religious and social aspects of the society but also, in the language used in the society.

Language as a Tool for Male Patriarchy

Sexism as a social phenomenon exists in different domains of every society and one of the domains where it is reproduced in the society is in Language. Its social effects, coupled with the growing influence of language have posed a serious problem for sociolinguists, some of who have laid out measures for its eradication. Nonetheless, sexism in language still exists, especially in levels where it has been made so subtle and has become very normative. One of such levels is the level of discourse, which combines different modes of language to convey meaning. The study of this research work focuses on this level of language by citing specific instances of sexism in selected English-medium billboards in Ile-ife, Osun state, Nigeria. Sexism in language or more specifically, in English resides in different domains. These domains stretch from the morphological level, through the use of affixation, generic terms, titles, alignment of male and female terms and occupational lexemes; syntactic level, in the forms of metaphors, proverbs, phrasal verbs, riddles and jokes and semantic level, depicted by the extent at which some words such as master and mistress, governor and governess, callboy and call girl differ in meaning, to the discourse level.

The level of discourse which is the focus of this study involves language use beyond its grammatical categories to contain such things as pictures, symbols and several other modes of language. As a concept, discourse can be defined as a text whether written, spoken, visual or multi modal which produces specific meanings in a particular context and whose meanings can be appropriated from context. As explored in this study, one of the ways through which sexism is depicted at this level is through the advertisement media, precisely in billboards, which have become familiar features of the society such that any sexist connotation conveyed by their contents has become so normative and is being 
perceived as unusual. As a result of Language's social influence, the issue of sexism contained in Language has posed a serious problem for sociolinguists in the growth of gender inequality and has long been a heat topic in sociolinguistics, He (2010). Today, there are several scholarly studies devoted to language and sexism. Jane Sunderland, Sara Mills, Robin Lakoff, Julia Stanley, Dale Spender, Y.K. Yusuf, A.P. Nilsen are just a few of scholars whose research efforts have helped in bringing the issue of Sexism in Language to the awareness of language users.

\section{Review of Earlier Studies}

According to Edegoh, Asemah and Okpanachi (2013), the workings of gender ideology and asymmetrical power relations in discourse are presently assuming quite subtle forms in modern societies, albeit in different degrees and ways in different communities. One of the media through which sexism is portrayed in discourse is the advertisement media or billboards, more specifically. Edegoh, Asemah and Okpanachi (2013) describe billboards as the branch of outdoor media targeted at a mobile audience, usually characterized by attractive models, images and catchy slogans and is used to reinforce recall of brand names and payoffs. Like other media of advertising, billboards are used to convey information about a product or service. Beyond informing however, their contents also stimulate ideas, some of which may be bias, among the viewers. As regards this, different studies have been carried out relating to sexism at the level of discourse. The bulk of their findings reveal that the (pictorial) representation of women in billboards is usually defining or stereotypical. According to Sheehan (2014), given that men and women differ in different ways, it should not be surprising that advertisements portray men and women differently. Although, these portrayals vary based on the medium in which they appear, Sheehan (2014), citing Peak, Nelson and Viella (2011), agrees that internationally, advertising still conforms to traditional gender portrayals. Globally, women are much more likely to be portrayed as dependent in advertising and much more likely to be pictured at home or in closed places, such as a market place, a supermarket, a classroom, or boutiques, Cheung and Leung (2014). Exploring women's portrayal in magazines' advertisements from Britain and Morocco, Habiba (2008) reveals that women are still considered responsible for the home and family life, as well as responsible for keeping their beauty and physical appearances attractive and seductive, not for their own self-esteem but for men's pleasure and satisfaction. Citing Craig (1992), Ali and Shahwar (2011) assert that for decades, women have been portrayed as housewives, dependent on men and attractive objects in advertising. The woman is therefore used as a body rather than somebody. The women have been portrayed in media as men would like to see them; beautiful creatures, submissive mothers and efficient house keepers. Women are viewed as "things", objects of male sexual desire, and part of the merchandise rather than people. In a study conducted by them, they reveal that most of the females are shown engaged in domestic tasks such as cooking, washing clothes, cleaning their kitchens, and beautifying their personalities.

According to them, the results show that the stereotypical approaches that followed these commercials gave the impression that women at home have no valid interest in their life except worrying about the perfection of their house, their clean shining floors, immaculate laundry and cooking.

Also, women are often portrayed in decorative roles, where they are depicted as passively decorating the commercial and disengaged from the product, Plakoyiannaki and Zotos (2008). According to Sheehan (2014), many decorative depiction of women tend to show women in sexual and alluring positions. Citing Paff and Lakner (1997), Sheehan (2014) states that decorative roles are seen as arguably representing society's view of the appropriate position for women in the society, which is passive. Citing Simmons (1986) further, he states that when decorative and sexual imagery is used, advertisements often include non-verbal cues as an indication that women lack authority and possess less power than men. Men, on the other hand are portrayed with characteristics of dominance and control. Unlike the women, they are mostly shown outside the home. For instance, the locations of the public service announcements studied by Cheung and Leung (2014) show males outside of commercial buildings, in a construction site, a public area or a park. In advertising, while men are often portrayed in the following ways: alert and conscious of surroundings, standing upright, eyes open and looking around, bodies are controlled, mean expression on face, gripping things tightly with hands, hands in pockets, serious and physically active, women are portrayed in as touching self, caressing an object, lying on the floor, sitting on a bed or chair, eyes closed, not alert, confused, vulnerable, body contorted, dressed like a child, holding an object or a man for support, sexy and sexually available, seductive, playful and careless. Thus, according to Nowosenetz (2007), the stereotypical portrayal of men still remains as dominant, intelligent and strong.

To assert this further, Cheung and Leung (2014) state that in addition to pursuing careers, males were portrayed with occupational diversity. For example, males were portrayed as a seller in the market place, a construction worker, a waiter, a driver, a security guard, a businessman, and a medical professional, etc. However, females were usually depicted as an office lady, a nurse, or a teacher or simply as a housewife or a mother. By comparison, male roles were more technically oriented and more strength demanding; while female roles were domestically oriented and caretakingdriven. As cited in Ali and Shahwar (2011), Countless ads have portrayed women as passive, deferential, unintelligent, shy, dreamy, gentle, likely to be manipulated, helpless, and with body language depicting psychological withdrawal, submissiveness and supplication, Browne (1998). Men, on the other hand, have been portrayed as constructive, powerful, autonomous, achieving, and their body language denoted power, control and dominance. Consequently, a synthesis of the many accusations against advertising reveals that advertisements often present men and women in terms of power and dominion with the males' always in control or in charge.

In view of the globalization of gender role portrayal in advertising, it is however argued that women stereotypes vary 
in extent based on different cultures. According to Cheung and Leung (2014), media in Asia tended to show more stereotypes than Western media. Their study which investigates gender ideologies by providing insight on the portrayals of females and males in health-related Public Service Announcements in Hong Kong reveal that compared to Chinese women, American women experience more equality and less discrimination. Asserting this, Sheehan (2014) states that in some parts of the world, women are shown as workers rather than homemakers. These 'equitable' portrayals can be attributed to a number of reasons, one of which is that the substantial number of women holding positions at a range of media organizations is working professionally to present a more realistic view of men and women in the media. Nonetheless, Habiba (2008) reveals that in some other parts of the world, Britain and Morocco, more specifically, women are not portrayed as equal to men, although as a result of the influence of cultural values on the content and messages of advertising, emphasis on female role portrayals are more stressed in Britain than in Morocco. According to Sheehan (2014), non-traditional images of men are also portrayed in advertising. These images show men as doing housework or taking care of the children. These roles have however been tagged as problematic and criticized as not portraying equality. This is because of the imbalance of images that show men in traditional homemaking situations. Hence, a large per centage of this portrayal of men in advertising have been debunked and tagged inaccurate.

\section{Methodology}

In carrying out this research, ten bill boards erected at different places in Ile Ife were carefully selected out of the numerous ones available in the city known as the source of all Yoruba people in the world. Photographs of the advertorial billboards for that express the gender differentiation were selected and literarily analysed based on literary theories like that of Wodak 2001 manifestation of transparent structural relationship in language use, Halliday, 1984 functional grammar and semiotic resources, as well as Blommaert and Bulcaen 2000

\section{RESUlTS AND DATA ANALYSIS}

In order to meet the aim and objectives of this study, Critical Data Analysis has been employed as the analytical framework because it analyses, according to Wodak (2001), "opaque as well as transparent structural relationships of dominance, discrimination, power and control as manifested in language". It states that discourse, being socially constitutive as well as socially conditioned is an opaque power object in modern societies and thus aims to make discourse more visible and transparent by investigating critically how social inequality is expressed, signalled, constituted, legitimized and so on by language use as once used in Blommaert and Bulcaen (2000). Each bill board advertisement picture was thoroughly discussed pointing out the act of bias against the women by creating the impression that men are stronger while women are only for appeasing people with their beauty.

Critical Discourse Analysis however does not have a unitary theoretical framework. Rather, it encompasses a range of approaches. As a result, this study also makes use of Kress and Van Leuven's Socio-Semiotic Approach for its data analysis.

\section{DisCUSSIONS}

The study's discussion was adopted the Socio-Semiotic approach. This approach explores ways of analysing visual images and paying attention to the multi semiotic character of most texts in contemporary society. It relies on Functional Grammar developed by Halliday $(1984,1995)$. Its main purpose is to describe the semiotic resources used in a text, such as point of view, whose distinct possibilities open a potential meaning for discrimination, power, inequality, etc. This approach establishes different kinds of meaning in its analysis. These meanings are:

a. The Representational meaning: This is the meaning represented in an image. It can be narrative or conceptual. The narrative aspect shows the participants as involved in an action, as used in advertising, while the conceptual aspect represents characters focusing on their essence and symbolic attributes through size, position, and colour or lightening. It entails a classification of participants in terms of their stable and timeless essence. It is equivalent with Halliday's ideational function. In some books, the representational meaning is also called the visual representation of meaning.

b. The interactive meaning: Since visual images represent an interaction among the participants represented in the image, the producers and their viewers, the interactive meaning shows the relationship between the observers and the world represented in the image. These images may depict petitioning, intimacy, etc. through visual contact or gaze, angle, point of view, etc. For instance, the angle at which an image is represented creates an attitude towards the viewer. According to Godeo (2005), from the frontal angle, an image may create subjectivity and involvement towards the viewer. However, from an oblique angle, it may create an attitude of detachment and an avoidance of any subjectivity. The interactive meaning is equivalent with Halliday's interpersonal function.

c. The compositional meaning: The placement of elements in an image, according to Kress and Van Leeuwen point out different informative values. For instance, elements placed at the top of an image have an ideal value contrary to the real characters situated at the bottom. Also, elements with a special salience in their composition on account of their size, colour or fronting may be highlighted as well. The compositional 
meaning thus account for the organization of elements in the image. It is equivalent with Halliday's textual function.

As a result of the descriptive nature of critical discourse analysis and the socio-semiotic approach, the analysis of this study is therefore, mainly qualitative.

Billboard 1(B1): Husband and Wife watching Television programmes

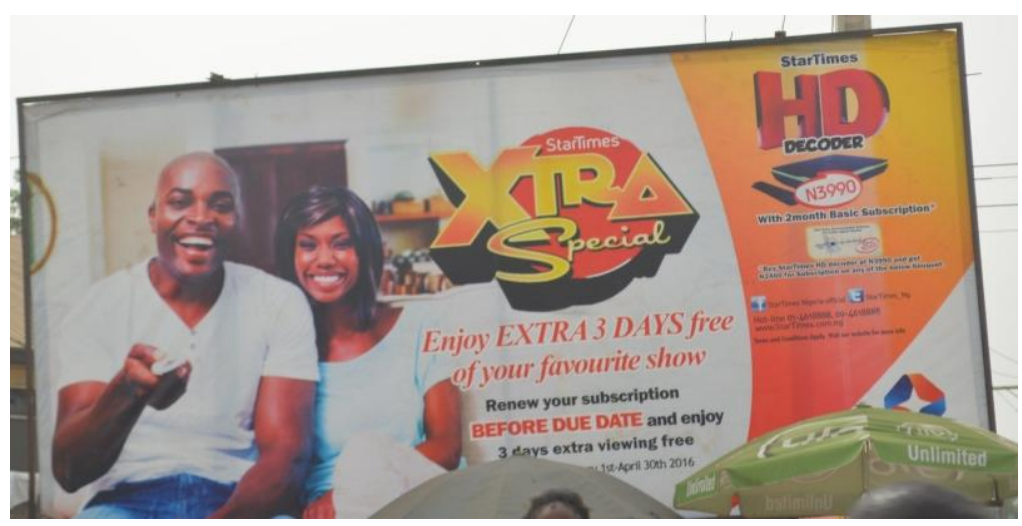

\section{Representational Meaning:}

B 1 contains the image of a young man and woman seemingly sitting side by side in a house and watching TV. Other features of the datum are specific information about the brand and product being advertised. These other features, for the purpose of this study, will not be subjected to analysis. In relation to the representational meaning, the image of the young man and woman draws upon the representation of human participants involved in a narrative process. By narrative process, it means that the participants are involved in an action. The posture of the participants depicts familiarity which connote that the duo are a couple. Also, their facial expressions show that they are apparently enjoying the show.

Nonetheless, although the image shows the couple sitting side by side, a closer look clearly shows that the frame of the man's body is in front of the woman, a position which places the woman behind the man. In addition to this, the man also controls the remote to the television both participants seem to be watching while the woman does nothing but smile passively.

These actions and posture thus represent the woman as passive and submissive while the man is literally represented as the one with the control, even in state of leisure and relaxation.

\section{Compositional Meaning:}

While every other feature of B1 is placed at the right side and are presented as new information, the image of the participants is placed at the left side of the billboard, a placement which according to Kress and VanLeeuwen represents things already known and 'often taken for granted'. This portrays the normalcy of the stereotypical representation of men and women in billboard advertisements.

\section{Billboard 2 (B2)Advertisement of Gilder Beer Drik}

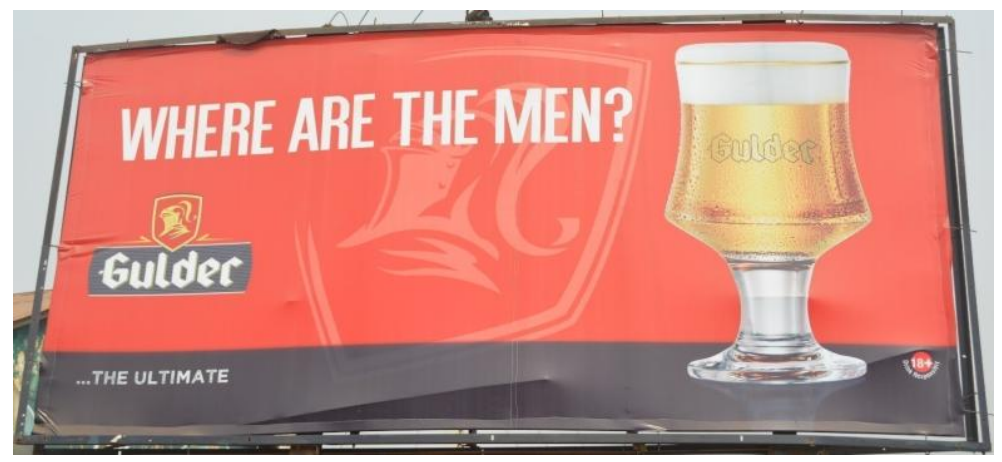

\section{Representational Meaning:}

In relation to the representational meaning, the process represented in Billboard2 is conceptual. By conceptual, it means that no action is taking place. The data will be therefore classified in terms of symbolic attributes through size, position, and colour. Unlike B1, there are no human participants represented in B2. The only image shown is a glass of the alcoholic drink, Guilder, with an accompanying verbal message which reads "WHERE ARE THE MEN?" Other features of the datum are the brand name, logo and slogan, which says "drink responsibly". Considering the fact that in Nigeria, both the male and female gender drink alcohol, the entire image however represents an invitation to just the men, which in turn signifies the exclusion of women. 


\section{Interactive Meaning:}

i. Point of Interaction: The image is represented from the frontal angle, which portrays an attitude of boldness. Also, the vertical angle representation of the image connotes height, power and superiority. According to Olateju, Oyebode and Ademilokun (2014), an image represented vertically may depict strength.

ii. The Use of Colours: The prevalent colours in B2 are red, black, white and gold. Complementing the fact that the drink, being alcoholic is sometimes called a strong drink, the colour red highlights the whole message, representing strength, vigour and a daring ability. These are features which society commonly associates with the men. The verbal text "WHERE ARE THE MEN?" is highlighted in white, a colour which represents truth and transparency, thus, justifying the exclusion of the women from something strong. The drink itself is Gold, which represents royalty, with the glass standing firmly on the black surface which traverses the bottom of the billboard. Black represents seriousness or mystery, which are features from which the women have also been excluded.

\section{Compositional Meaning:}

The verbal message which typifies the exclusion of women is placed on the left side of the billboard, along with the brand name, logo and slogan. According to Kress and Van Leeuwen, images placed on the left represent information which is given and 'often taken for granted'. Like B1, this also portrays the normalcy of the stereotypical representation of men and women in billboard advertisements.

Billboard 3 (B3): Advertisement of Turbo King Beer

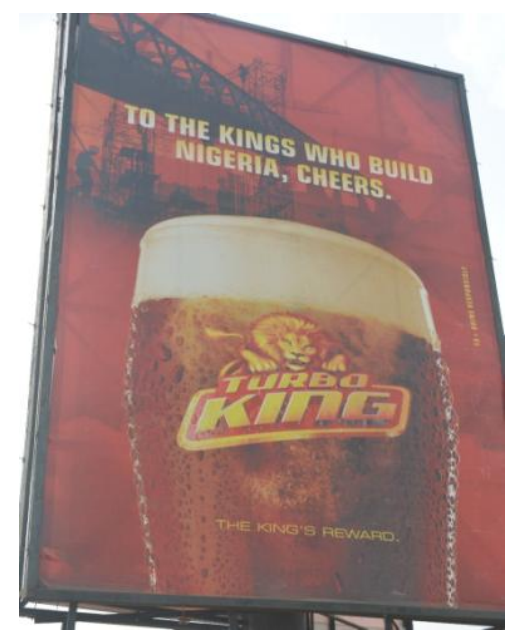

\section{Representational Meaning:}

In relation to the representational meaning, the process represented in B3 is conceptual. The image shown is a fore grounded glass of the alcoholic drink, Turbo King, with an accompanying verbal message which reads "TO THE KINGS WHO BUILD NIGERIA, CHEERS." In the background is an image of men working at a construction site. This image complements the idea of men building to whom the accompanying message is dedicated as a toast. Other features of the data are the brand name, logo symbolized by a lion, which signifies strength and royalty and the slogan, which says "the king's reward". B3 thus represents the male gender as kings and nation builders.

\section{Interactional Meaning:}

i. Point of Interaction: Like B2, the image is represented from the frontal angle, which portrays an attitude of boldness. Also, the vertical angle representation of the image connotes height, power and superiority.

ii. The Use of Colours: The colours used in B2 and B3 are very similar. This may be attributed to the fact that they are both advertisements for alcoholic drinks. Like B2, the prevalent colours in B3 are red, black and gold. The colour red also highlights the whole message, representing strength and vigour. The drink, the accompanying verbal message and the brand trademarks are all presented in gold, which represents royalty. Black is used for the construction site and workers which represents seriousness. From all these features, the women have been excluded.

\section{Compositional Meaning:}

The placement of the message "TO THE KINGS WHO BUILD NIGERIA, CHEERS", which also typifies the exclusion of the female gender, at the top of the billboard portrays the message as ideal or idealized, according to Oyama's (1998) Description of Visual Semiotic. Nonetheless, like most stereotypical messages, it can also lead to the forming of an ideology in the viewers which excludes women from tasks involving strength and a daring ability, such as Nation building.

Billboard 4 (B4): Advertisement of a Nigerian Musician called Cloud 


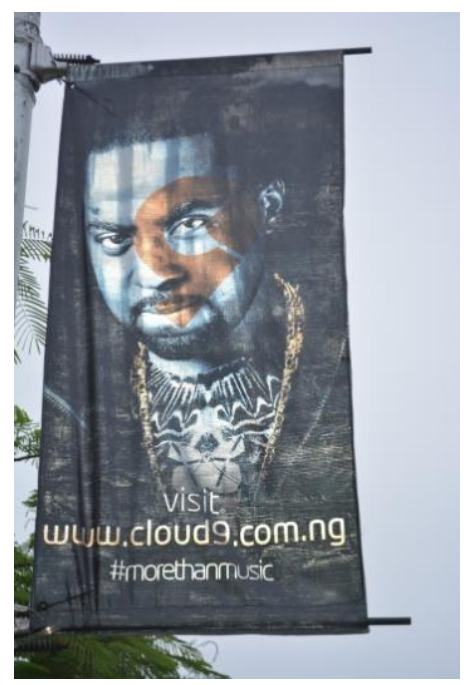

\section{Representational Meaning:}

In relation to the representational meaning, the process represented in B4 is conceptual. It shows a male model with clenched lips and a hard stare. Other features of the datum are the website and the slogan of the service, 'cloud 9' being advertised. The facial gesture exhibited by the represented participant in B4 represents the model as serious, fearless and daring.

\section{Interactive Meaning:}

i. Gaze: The model in B4 maintains eye contact with the viewers. More still this gaze takes the form of a hard stare which passes the male off as strong, fearless and daring.

ii. Angle of Interaction: The image of the male model is presented from the frontal angle and in a vertical position, where like B3, signify boldness.

iii. Colour: The predominant colours used in B4 are black and red. The whole board is painted in black which connotes seriousness. The model's facial expression further complements this assertion. Red is also used to connote strength. It is important to note that as in B2 and B3, these colours have been used in billboards where men are included and represented.

Compositional Meaning: The represented participant occupies every part of the billboard (from the top to the bottom). This placement foregrounds his appearance and makes prominent everything he signifies.

Billboard 5 (B5)Promotion and advertisement of a Body cream lotion

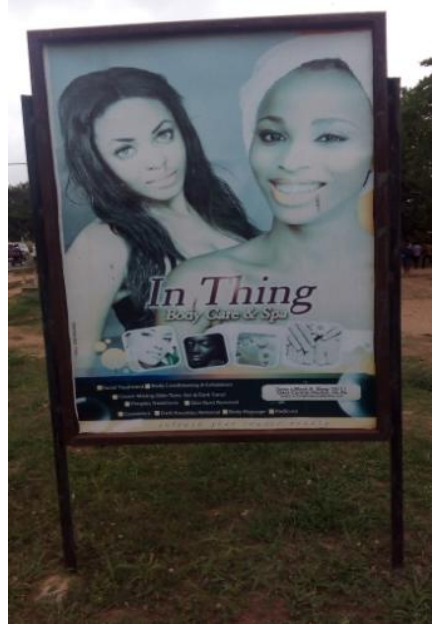

\section{Representational Meaning:}

In relation to the representational meaning, the process represented in B5 is conceptual. The data contains an image of two ladies posed for a photograph, in such a way that they individually occupy both sides of the billboard. This is accompanied with a verbal message that reads "In Thing". In Nigeria, 'In thing' is a slang for whatever is trending. Other features of the datum are: the services of the beauty spa being advertised (also presented in pictures which portray the female body in parts) and other trademarks. For the purpose of this study, these other features will not be analysed. The lady on the right has nothing on except a towel tied around her head and chest. The lady on the left is wearing a black strapless singlet which reveals a slight cleavage. They are also both wearing a smile. By portraying both female participants as attractive and sexy in an attempt to advertise the beauty spa, sex appeal and physical attractiveness are 
therefore represented as the trend.

\section{Interactive Meaning:}

\section{Contact/Gaze:}

The represented participants maintain eye contact with the viewers. According to Oyama (1998), Olateju, Oyebode and Ademilokun (2014), by maintaining eye contact with the viewers, the represented participants perform an act of demanding, or in a more precise sense, inviting. This gaze is further enhanced by the smiles and poses of the participants.

\section{Compositional Meaning:}

The image covers the whole billboard, except the bottom. The verbal message "In Thing", which typifies what is being represented as trending is also strategically placed at the centre. Images or messages placed in these positions, being prominent, according to Oyama (1998) are used to drive an ideology. In B5, it emphasizes the notion that women are often portrayed in relation to their sex appeal or as concerned only about physical attributes, Habiba (2008).

\section{Billboard 6 (B6): Advertisement of a Unisex Saloon Centet}

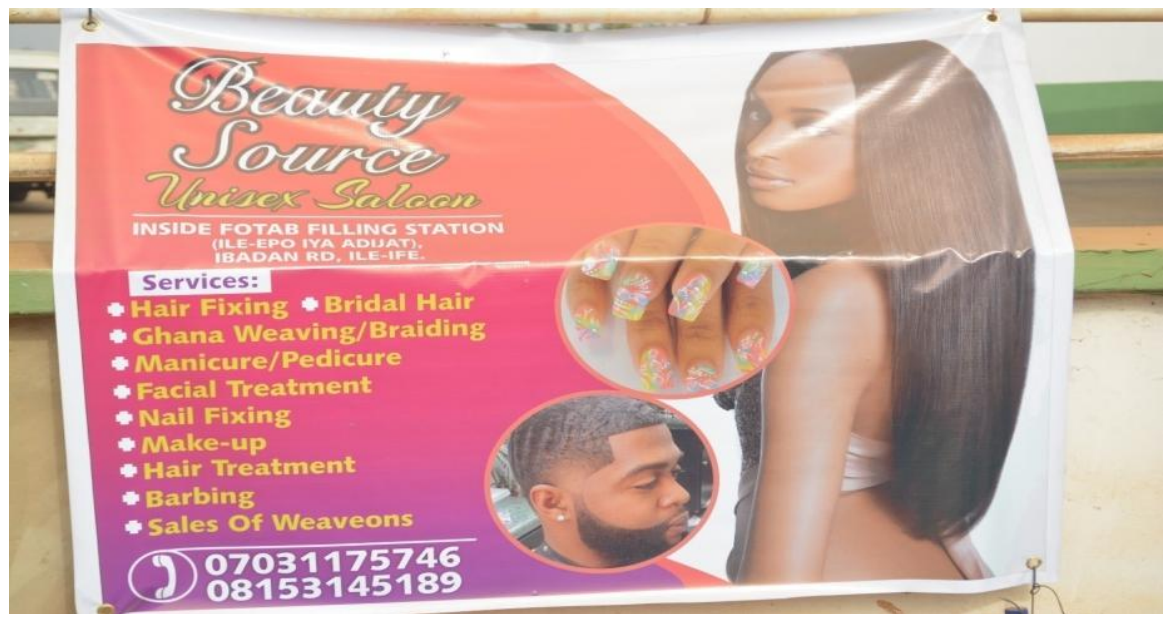

\section{Representational Meaning:}

In relation to the representational meaning, the process represented in B6 is also conceptual. The features of the data are the image of a lady, the trademarks of the beauty salon being advertised, contact address and services which are represented in images containing a male participant and fingernails (a part of a female body which can be used to represent a female). All the images are portrayed to visually propel the services of the salon. Nonetheless, though the salon is unisex, of the ten services itemized on the billboard, only one, barbing (item 9), relates to a man. This makes the billboard predominantly feminine. Also, the lady's image is foregrounded, having been made larger than the others. She is half naked and she possesses an attractive skin, face and hair. All of which are intended to attract customers. Like B5, the lady also represents sex appeal and physical attractiveness.

\section{Interactive Meaning:}

\section{i. Contact/Gaze:}

There are two human participants on the billboard. Of the two, only the lady maintains eye contact with the viewers. Complemented by her seductive posture and outfit, this contact, like B5, signifies an invitation.

\section{ii. The Use of Colours:}

The prevalent colours used in B6 are white, peach, pink, purple and yellow. Apart from the connotative meanings that are individually attached to these colours, these colours, characterized by their mildness, softness, cheerfulness and brightness are usually associated with women. These are unlike the colours used to represent men in B2, B3 and B4 which characterize strength and vigour.

\section{Compositional Meaning:}

The positioning of the represented participant on the right side of the billboard is significant in the sense that it presents the model and everything she represents as something new of which is intended of the viewers to explore or find out. Usually, information about the services and brand is placed on the right, this deviation therefore calls undue attention to the model and everything she represents.

Billboard 7 (B7)Advertisement of a Photograph Company 


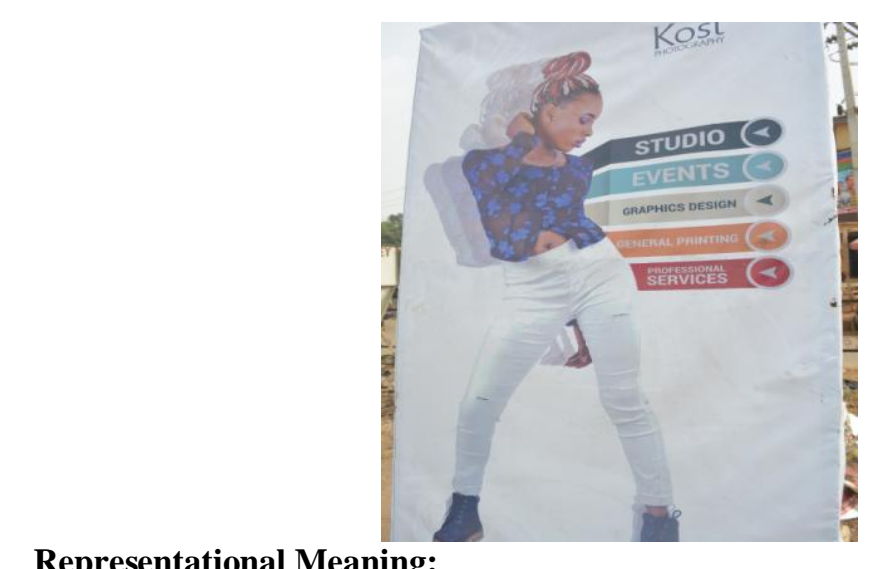

\section{Representational Meaning:}

In relation to the representational meaning, the process represented in B7 is conceptual. The only represented participant is a lady. Other features of the data are the trademarks and the services of the photography studio being advertised. The lady strikes a seductive pose, wearing a pair of converse, a white trouser and a transparent t-shirt which reveals her belly button and upon closer look, her bra. She is represented as sexy.

\section{Interactive Meaning:}

\section{Contact/Gaze:}

The participant in B7 does not maintain eye contact with the viewers. According to Olateju, Oyebode and Ademilokun (2014), an averted gaze may imply an offering. Hence, the model strikes a sexy pose but looks away which indicates that she is offering herself in service.

\section{Compositional Meaning:}

While every other information is on the right side of the billboard, the represented participant is on the left. A position which indicates information often taken for granted. This emphasizes the normalcy of the sex appeal stereotype conferred on women in advertisements.

\section{Billboard 8 (B8): Advertisement of Body Cream}

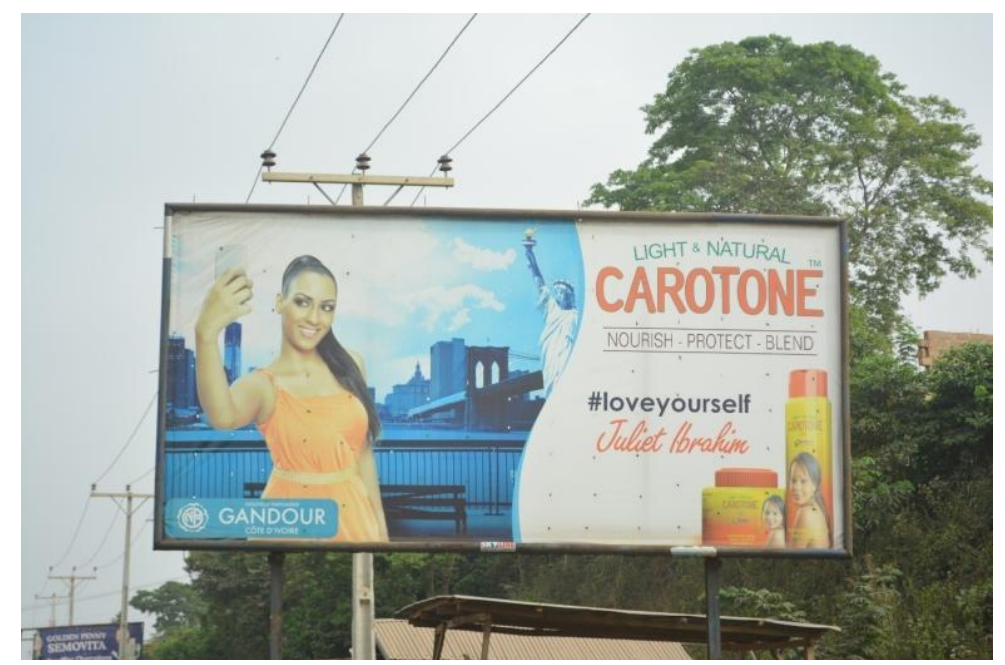

\section{Representational Meaning:}

In relation to the representational meaning, the process represented in B8 is narrative. It shows a young lady taking a self in Paris with a famous statue of liberty. Other features of the data are the trademark of the cream being advertised, a signature of the model which says 'Juliet Ibrahim' and a verbal message "\#love yourself", apparently admonishing women to love themselves. Considering the fact that the product being advertised is a body cream, this message emphasizes the assertion that women have the responsibility to keep their physical appearance attractive, Habiba (2008). Also, unlike prior advertisements where women are portrayed flaunting their sex appeal, this image shows a fairly modest young lady probably on a holiday and apparently having fun. Nonetheless, as asserted by Chung and Leung (2014), this portrays women as concerned with trivial or playful things such as taking a selfie.

\section{Interactive Meaning:}

\section{The Use of Colour:}

The prevalent colours on the billboard are sky blue, orange, white and green. Asides their individual connotations, these colours are effeminate, as they characterize mildness and softness, which are features often associated with women in Nigeria. 


\section{Compositional Meaning:}

Like B7, the information about the product is placed on the right side of the billboard, signifying new information, while the image of the lady which ideologically portrays women as concerned with trivial things is on the left side, signifying, like most stereotypes that this knowledge is often taken for granted.

Billboard 9 (B9): Advertisement of a Communification out fit in Nigeria

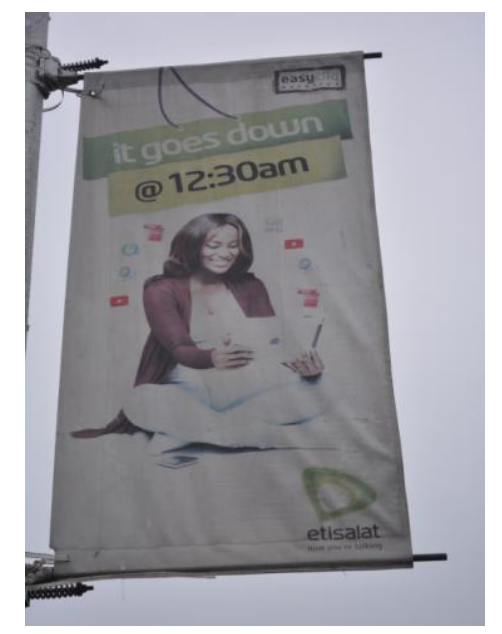

\section{Representational meaning:}

The represented participant in B9 is a lady who is casually seated. She is holding a tablet and is surrounded by tiny icons of different social media platforms. The way in which she holds the tab, complemented by her facial gesture suggests that she is taking a selfie. This image is accompanied by a verbal message which reads, "It goes down @ 12:30am."

'It' there is an exospheric reference for fun, while 'goes down' is a virtual slang for 'is happening'. The use of a virtual slang depicts that the advert is directed towards a young audience. Other features of the datum are the trademark of the network service being advertised. The image complemented by the verbal message represents the lady as playful, having fun and enjoying herself.

\section{Interactive Meaning:}

\section{The Use of Colours:}

B9 contains a lot of colours. One thing that is however common to all of them is that these colours are predominantly effeminate. Effeminate colours, such as white and green, represent characteristics such as mildness, softness, etc. This is in contrast with colours which are used to represent men.

\section{Compositional Meaning:}

The represented participant is placed at the centre, a position which makes prominent the model and everything she represents. The verbal message which typifies fun is significantly placed at the top of the billboard. This placement further drives the ideology that women are associated with playful things.

Billboard 10 (B10): Advertisement of a Communication outfit in Nigeria

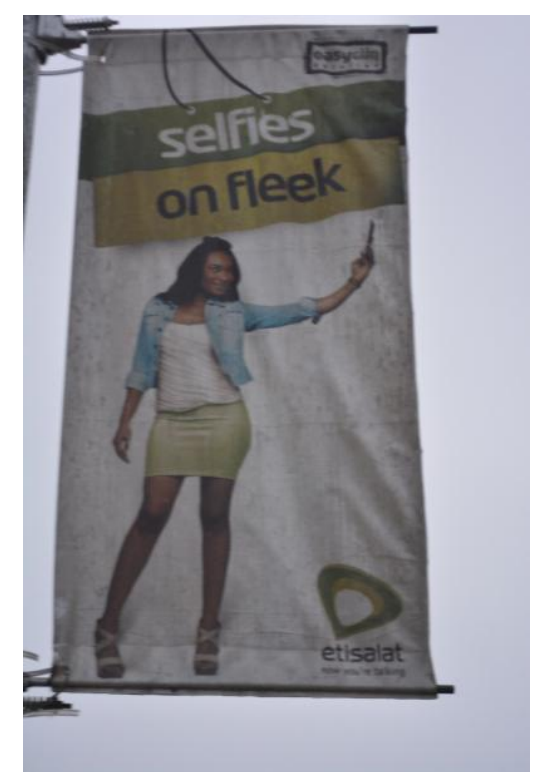




\section{Representational meaning:}

Like B9, the participant represented in B10 is a lady. She is standing, posed for a photograph, a selfie more precisely. Her posture is quite casual and depicts nothing sexual. Nonetheless, she is wearing a short skirt which reveals a large part of her thighs and legs and heels, which further elongate her legs. Aside these parts of her body, no other part is revealed. The image is accompanied by a verbal message which reads, "Selfies on Fleek". The virtual slang which indicates public approval signify that the advertisement is projected at a young audience. This is asserted by the fact that the billboard is situated within a University's campus. The other features of the datum are the trademarks of the network service being advertised. Like B9, the lady in B10 is represented as playful, relaxed and unserious.

\section{Interactive Meaning:}

Gaze: The gaze of the represented participant is averted which although is meant to direct the attention of the viewer to the action represented, also directs the attention of the viewers to other visible parts of her body which portrays her as offering herself.

Compositional Meaning: Like B9, the represented participant is placed at the centre, a position which makes prominent the model and everything she represents. The verbal message which accompanies it is also placed at the top of the billboard. This also drives the ideology that women are associated with trivial things like selfies.

\section{CONCLUSION}

Findings reveal that there is asymmetrical power relation in terms of dominance and subordination between a man and a woman on one hand, and the portrayal of men in terms of physical attributes, such as strength, vigour and a daring ability, as well as the portrayal of women in terms of sex appeal, physical attractiveness and as concerned with trivial, unserious and playful things in Nigeria judging by the analysed bill boards. Based on these findings, the study therefore concludes that there are indeed, instances of sexism in the identified billboards and although this study has not claimed generalizations, it has successfully achieved its aim of citing specific instances of sexism in English-medium billboards in Ile-Ife Nigeria..Based on the conclusion, this study recommends that more researches should be carried out involving a wider range of billboards and other media containing multimodal discourse. Also, the study recommends that every aspect of language should be scrutinized and researches on sexism should not be limited to linguistic levels only.

\section{REFERENCES}

[1] Ahmad, N. (2009). Sexism in Language. A Thesis Submitted to the Department of English and Humanities of BRAC University. Retrieved from: http://www.dspace.bracu.ac.bd retrieved on the 4th March 2019.

[2] Ali, S. and Shahwar, D. (2011). Men, Women and T.V Ads: The Representation of Men and Woman in the Advertisements of Pakistani Electronic Media. Journal of Media and Communication Studies, 3(4), 151-159.

[3] Blommaert, J. and Bulcaen, C. (2000). Critical Discourse Analysis. Annual Review of Anthropology, 29, 447-466. Retrieved from http://www.jstor.org/stable/223428 (retrieved on the 6th of February, 2019.

[4] Cheng, K. and Leung, V. (2014). Reinforcing Gender Stereotypes: A Critical Discourse Analysis of Health-Related PSAs in Hong Kong. American International Journal of Social Sciences, 37-48. Volume3 no3.

[5] Edegoh, L. Asemah, E. and Okpanachi, R. (2013). Guinness Stout Billboard Advertisement and Gender Repesentaion: Views of Media Practitioners in Anambra State, Nigeria. Journal of New Media and Mass communication, 18, 55-64. Retrieved from www.iiste.org 20th June, 2018.

[6] Fairclough, N. (1995). Critical Discourse Analysis: the Criitical Study of Language (2nd ed.). New York: Longman Publishing.

[7] Fajobi, E. and Olusegun-Joseph, Y. (2013). Language and Gender in Contemporary English Usage. In A. Adekoya, Adegoju, A \& W. Adegbite (Ed.), Use of English: a Manual on Communicative Skills for Tertiary Institutions (pp. 239-247). Ile-Ife: Department of English, Obafemi Awolowo University.

[8] Habiba, C. (2008). Gender and the Language of Advertising: a Sociolinguistics Analysis of Women's Representation in British and Moroccan Magazines Advertisements. An Unpublished Thesis.

[9] He, G. (2010). an analysis of sexism in English. Journal of language teaching and research, 1, 332-335.

[10] Krauss, R. and Chiu, C. (1998). Language and Social Behaviour. In D. F. Gilbert, Handbook of Social Psychology (4th ed., pp. 41-88). Boston: McGraw-Hill.

[11] Lei, X. (2006). Sexism in Language. Journal of Language and Linguistics, 5, 87-94.

[12] McCarthy, M. Mattiessen, C and Slade, D. (2002). Discourse Analysis. In N. Schmitt, An Introduction to Applied Linguistics (pp. 53-73). London: Arnold.

[13] Nowosenetz, T. (2007). The Construction of Masculinity and Feminity in Alcohol Advertisements in Men's Magazines in South Africa: a Discourse Analysis. Dissertation Submitted to the Department of Psychology, University of Pretoria.

[14] Olateju, M. Oyebode, B and Ademilokun, M. (2014). Doing Multimodal Discourse Analysis: a Practical Approach to Multimodal Analysis. Ibadan: College Press and Publishers Limited.

[15] Oxford Advanced Learners' Dictionary. International Student's Edition 8th Edition, London. Oxford University Press.

[16] Oyama, R. (1998). Visual Semiotics: a Study of Images in Japanese Advertisements. A Thesis Submitted to the University of London.

[17] Plakoyiannaki, E. a. (2008). Female Role Stereotypes in Print Advertisements. 1411-1431. Retrieved from www.emeraldinsight.com/0309-0566.htm (retrieved on the 10th of February, 2019).

[18] Sapir, E. (1921). Language: an Introduction to the Study of Speech. New York: Harcourt, Brace.

[19] Sheehan, K. (2014). How Gender Shapes Meaning. In K. Sheehan, Gender and Advertising.

[20] Sunderland, J. (2006). Language and Gender: an Advanced Resource Book. USA, OXON, CANADA: Routledge . 
[21] Williamson, J. (2002). Decoding Advertisement; Ideology and Meaning in Advertising. New York: Marion Boyers.

[22] Wodak, R. and Meyer, M. (2001). Methods of Critical Discourse Analysis. Califonia: Sage Publications.

Bolanle Tajudeen Opoola was born at Oyo town, Nigeria on the 26th of May 1959. He has B A, MA and Ph.D in Applied Linguistics from the University of Calabar, Nigeria between 1986 and 2000.

He has been a language and Linguistics Lecturer and researcher for more than twenty years at the College and University levels. $\mathrm{He}$ is presently the Head of Linguistics and Languages department and Acting Dean, Faculty of Arts, Federal University Oye Ekiti, Nigeria. He has published several books including Topics in Applied Linguistics by Executive publishers, Owerri, and Competence and Performance In English by Emola-Jay publishers, oyo and about thirty articles on Linguistic topics of many learned societies.

Dr. Bolanle Tajudeen Opoola is a member of Management Institute of Nigeria and Fellow of Institute of Policy Management and development.

Folorunso Emmanuel Awoniyi was born in Osun State Nigeria where he had his primary, secondary education before proceeding to the University of Ibadan for first and higher degrees in Linguistics.

$\mathrm{He}$ is currently a doctoral degree student of Applied Linguistics at the University of Ibad .an with flair for Clinical and pedagogical linguistics.

He has contributed more than ten articles in the field of Linguistics in many reputable index Journals 